\title{
Effect of Spacer Length on the Specificity of Counterion-Cationic Gemini Surfactant Interaction
}

\author{
Rohit Sood ${ }^{1}$, Juha-Matti Alakoskela ${ }^{1}$, Anjali Sood ${ }^{2}$, Pavol Vitovič ${ }^{1, \#}$ and \\ Paavo K.J. Kinnunen ${ }^{1, *}$
}

${ }^{1}$ Helsinki Biophysics and Biomembrane Group, Department of Biomedical Engineering and Computational Science, Aalto University, P.O.B. 12200, FIN-00076, Espoo, Finland

${ }^{2}$ Department of Chemistry, Laboratory of Inorganic Chemistry, Aalto University, P.O. Box 16100, Fl-00076 Espoo, Finland

\begin{abstract}
Aqueous solutions of three dicationic quaternary N,N-dimethylammonium gemini surfactants with identical hydrocarbon tails (N-hexadecyl) separated by flexible two, four, and six carbon atom spacers (di-, tetra-, and hexamethylene), abbreviated as G2, G4, and G6, respectively, were characterized using dynamic light scattering (DLS), Langmuir balance, differential scanning calorimetry (DSC), and microscopy in the presence of varying concentrations of sodium salts of fluoride, chloride, bromide, and iodide. Clear dependence on counterion species was evident in the surface activity of the geminis, as follows. In $0.1 \mathrm{mM}$ salt minima in surface tension and hence presumably the highest affinity for G2, G4, and G6 were observed with fluoride/chloride, bromide, and iodide, respectively. This same ion specificity of G2, G4, and G6 was evident also in the changes of average hydrodynamic diameters $\left(Z_{\mathrm{av}}\right)$ with temperature. More specifically, maximum in $Z_{a v}$ for $G 2$ was observed in $100 \mathrm{mM} \mathrm{NaCl}$, for $\mathrm{G} 4$ in $100 \mathrm{mM} \mathrm{NaBr}$, and for $\mathrm{G} 6$ in $1 \mathrm{mM} \mathrm{Nal}$. Our results demonstrate that spacer length has a profound impact on interaction of these surfactants with halide counter-ions of different sizes, controlling organization of these cationic geminis in the presence of salt. Importantly, our studies show that adjusting the headgroup structure it is possible to design amphiphiles, which can be used to bind specific metal ions in solution, for purposes such as water purification and mineral enrichment.
\end{abstract}

Keywords: Gemini surfactants, counterions, spacer length, ion specificity, surface pressure.

\section{INTRODUCTION}

Gemini surfactants, composed of two conventional surfactants connected by a spacer [1-3], are an interesting class of amphiphilic molecules which demonstrate a number of properties uncommon for conventional surfactants, including very low CMCs, high surface activities, and rich pleomorphic phase behaviours [4-6]. They are efficient catalysts in organic reactions, possess high surface activity, and exhibit anomalous concentration-dependent viscosity changes, aggregation, and micelle structures. Their unusual amphiphilic characteristics make gemini surfactants cost-effective and environmental friendly alternatives to conventional surfactants [7]. The chemical structure of geminis allows for chemical synthesis of a great variety of different surfactants, thus making these amphiphiles particularly interesting for applications requiring precisely controlled selfassembly, such as lipofection [8, 9-11]. The most widely studied geminis are dicationic quaternary ammonium compounds, referred to as $\mathrm{Cm}-\mathrm{Cs}-\mathrm{Cm}$,

*Address corresponding to this author at the Department of Biomedical Engineering and Computational Science (BECS), Aalto University, Otakaari 3, Fl-02150 Espoo, P. O. Box 12200, Fl-00076 Aalto, Finland; Tel: + 35850 5404600; Fax: + 35894702 3182; E-mail: paavo.kinnunen@aalto.fi

\#Current Address: Pavol Vitovic, Department of Nuclear Physics and Biophysics, Faculty of Mathematics, Physics and Computer Sciences, Comenius University, Mlynska Dolina F1, 84248 Bratislava, Slovak Republic; E-mail: vitovic@cordbloodcenter.sk where $\mathrm{m}$ and $\mathrm{s}$ stand for carbon atom number of alkyl chains and methylene spacer, respectively [12].

Aqueous properties of surfactants such as micelle formation, aggregation, and degree of ionization are affected by additives such as aromatic acids/salts [13], nucleotides [14], polyelectrolytes [15], and counterions [16]. Of particular and long-standing interest have been ion-specific effects of counter-ions on surfactant and colloid properties, rationalized according to Hofmeister series. The physical basis of Hofmeister series remained unclear for a considerable time, however, ubiquitous ion-specific effects of Hofmeister series have been recently explained by effects of ion polarizability on their solvation free energy in aqueous solutions and on interactions with nonpolar surfaces. lon-specific effects are well known from both biology and chemistry of chelators and ionophores, where specific distribution, chemical nature, and spacing of polar groups provides a high selectivity for specific ions. Recently, a novel mechanism allowing for specificity in ion interactions was suggested for a gemini surfactant with a rigid spacer. More specifically, commensurate lattice of charges in the presence of salt and gemini, resulting in surface crystallization of salt on gemini surface and leading to a sharp transition from micelles to giant vesicles to assemble into a nearly planar crystalline surface, enslaving surfactant 
membrane to the planar geometry favored by the ioncounterion lattice [7].

The spacer of a gemini surfactant can be rigid or flexible and to a varying degree hydrophilic, and is therefore expected to influence the aggregation properties, along with the length of hydrophobic tails. Further, spacer length also controls headgroup charge separation and chain packing [3]. In the present work, we studied specificity of counter-ion-gemini surfactant interactions with halides (viz. $\mathrm{Na}^{+}$salts of fluoride, chloride, bromide and iodide) and a series of dicationic quaternary ammonium gemini surfactants with flexible spacers of varying length. The studied cationic geminis have identical (C16) hydrocarbon tails with spacer lengths of 2, 4, and 6 carbon atoms. Interestingly, we observed a correlation between length of spacer and size of the counterion, evident in the self-assembly of these surfactants. At low salt and gemini concentrations the gemini with 2 carbon spacer showed strongest interaction with chloride, the gemini with 4 carbon spacer with bromide, and the gemini with 6 carbon spacer with iodide. The different salts also induced complex changes in the structure of gemini surfactant aggregates.

\section{EXPERIMENTAL}

\section{Materials and Methods}

$\mathrm{NaF}, \mathrm{NaCl}, \mathrm{NaBr}, \mathrm{Nal}, \mathrm{NH}_{4} \mathrm{Cl}, \mathrm{NH}_{4} \mathrm{Br}$, and $\mathrm{NH}_{4} \mathrm{I}$ were from Sigma (Steinheim, Germany) and were used without further purification. Cationic gemini surfactants with identical hydrocarbon tails but different spacer lengths i.e. dimethylene-1,4-bis(N-hexadecyl-N,Ndimethylammonium bromide (G2), tetramethylene-1,4bis(N-hexadecyl-N,N-dimethylammonium bromide (G4), and hexamethylene-1,6-bis(N-hexadecyl-N,Ndimethylammonium bromide (G6) (Figure 1) were synthesized as described elsewhere [17] and their structures verified by NMR $(200 \mathrm{MHz}$, Bruker, CA, USA). Concentrations of gemini surfactant stock solutions in chloroform were determined by gravimetric analysis [18] using a high precision electrobalance (SuperG; Kibron Inc, Espoo, Finland).

\section{Surfactant Dispersions}

Appropriate amounts of surfactant stock solutions were transferred into carefully cleaned test tubes and solvent was evaporated under a stream of nitrogen. Tubes were then sealed with parafilm and kept in vacuum overnight to remove any residual traces of solvent. The dry surfactant films were hydrated by deionised water (Milli RO, Millipore, Molsheim, France) or indicated salt solutions to yield a final surfactant concentration of $1 \mathrm{mM}$, followed by vigorous mixing and incubation for $45 \mathrm{~min}$ at $60^{\circ} \mathrm{C}$.

\section{Surface Activity Measurements}

Surface activity as a function of bulk concentration of $\mathrm{G} 2, \mathrm{G} 4$, and $\mathrm{G} 6$ in the presence of indicated concentrations of given salts, $\mathrm{NaF}, \mathrm{NaCl}, \mathrm{NaBr}$, or $\mathrm{Nal}$ was measured. Dilution series of 11 concentrations of surfactants were prepared in disposable 96-well plates (Greiner Bio-One, Kremsmünster, Austria) using a multichannel pipette, with surfactant concentration given as $c \cdot x^{n-1}$, where $x$ is the dilution factor (DF), $c$ is the concentration of cationic gemini in column 1 (i.e. $1.0 \mathrm{mM}$ ), and $\mathrm{n}$ increases from 1 to 11 , corresponding to columns 1 to 11 on the 96 -well plate. For DF $=0.4$, an aliquot of $70 \mu \mathrm{l}$ was transferred from one column to consecutive one, up to column 11, with a total volume of $175 \mu \mathrm{l}$ per well. Column 12 was filled with plain salt solution to provide a reference value for surface tension. Subsequently, $50 \mu \mathrm{l}$ from each well was transferred into corresponding well of 96-well plate (Dyneplates, Kibron Inc., Helsinki, Finland) for measurement of surface tension. The plate was then covered with a lid, and allowed to equilibrate for $90 \mathrm{~min}$ prior to recording of surface tension [19-20] using an 8channel surface tension microplate reader (Delta 8, Kibron Inc.). The instrument records value of surface tension by determining in triplicate maximum weight of meniscus adhering to a $0.5 \mathrm{~mm}$ diameter du Nouy probe upon its withdrawal from solution [21]. To minimize the impact of carry-over, plates were measured starting with column 12 containing salt solution without surfactant and then continuing towards increasing concentration of given gemini. The probes were automatically cleaned between each 96 -well plate by heating in the built-in electric furnace of tensiometer.

\section{Dynamic Light Scattering}

Mean hydrodynamic diameters $\left(Z_{\mathrm{av}}\right.$, in $\left.\mathrm{nm}\right)$ of gemini surfactants in the temperature range from 20 to $50{ }^{\circ} \mathrm{C}$, both in water and with indicated salts were determined by photon correlation spectroscopy at a scattering angle of $173^{\circ}$ (Zetasizer Nano ZS, Malvern Instruments Ltd., Malvern, UK). Surfactant dispersions (1 $\mathrm{ml}$, final concentration $1 \mathrm{mM}$ ) were loaded into standard plastic cuvettes (Malvern) and measured twice at each temperature, controlled by the Peltier elements of instrument. $Z_{\mathrm{av}}$ was calculated from the diffusion coefficient (D) using Stokes-Einstein equation $Z_{a v}=k T / 3 \pi n D$ where $k$ is the Boltzmann coefficient, $T$ 


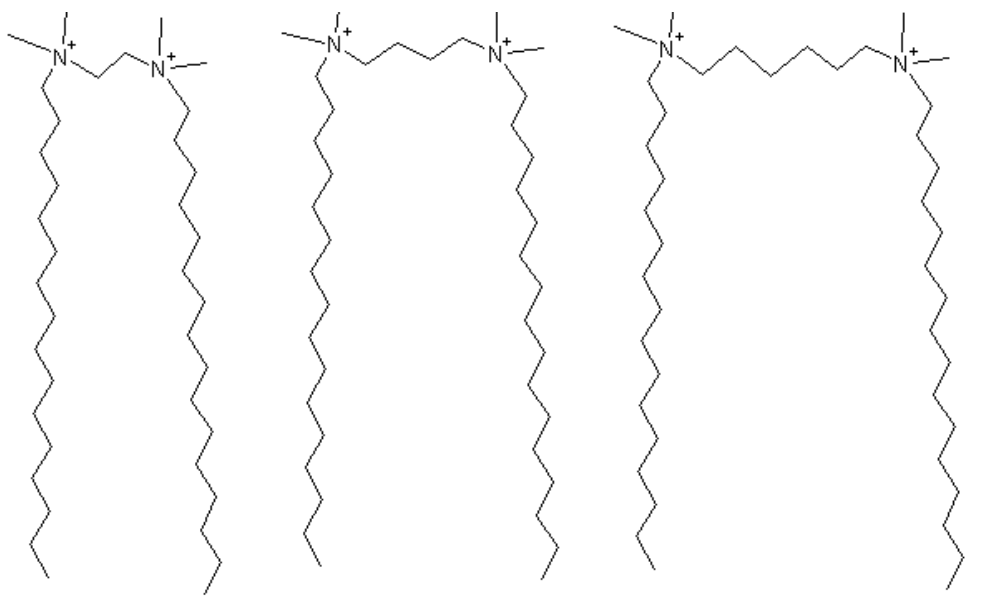

Figure 1: Structures of three cationic amphiphiles G2, G4, and G6 (from left to right) with identical hydrocarbon tails (C16) but differing in the lengths of their headgroup spacer.

the absolute temperature, and $\eta$ viscosity of the solvent.

\section{Differential Scanning Calorimetry (DSC)}

After hydration surfactant dispersions (final concentration $1 \mathrm{mM}$ ) were vortexed and loaded into calorimeter cuvette. A VP-DSC microcalorimeter (Microcal Inc, Northampton, MA, USA) was operated at a heating rate of 0.5 degrees per minute and data were collected during heating scans from 10 to $70^{\circ} \mathrm{C}$. Phase transitions $\left(T_{m}\right)$ were taken as temperatures at which endotherm reaches its maximum. The instrument was interfaced to a PC and data were analyzed using routines of the software provided by Microcal.

\section{Optical Microscopy}

An inverted microscope with differential interference optics (Olympus IX-70, Olympus, Tokyo, Japan) and with LCPlanFI 20x/0.40 objective was used for optical microscopy. The images were collected using a digital camera (D10, Canon Inc, Tokyo, Japan) attached to camera port of microscope. Surfactant suspension (1.5 $\mathrm{ml}$ ) with indicated [salt] was applied into a chamber with quartz glass bottom, heated from $24{ }^{\circ} \mathrm{C}$ to $50{ }^{\circ} \mathrm{C}$ within approx. 50 min by a Peltier thermal microscopy stage (TS-4, Physitemp, Clifton, NJ, USA), monitoring temperature by an immersed $\mathrm{Pt}-100$ probe (Omega, Stamford, CT, USA).

\section{RESULTS}

Solubility of G2, G4, and G6 in Different Salt Concentrations

Solubility of G2, G4, and G6 differed with different salt concentrations. G2, G4 and G6 were readily soluble in water as well as upto $100 \mathrm{mM}$ of salt concentrations for $\mathrm{NaF}, \mathrm{NaCl}$, and $\mathrm{NaBr}$. In the presence of Nal solubility of studied gemini's were quite low, for instance G2 and G4 was soluble in upto $40 \mathrm{mM} \mathrm{Nal}$, however, $\mathrm{G} 6$ was least soluble in Nal and caused immediate precipitation at [Nal] $>1 \mathrm{mM}$. Hence due to this solubility problem we carried out surface pressure, DLS, and DSC experiments in the range of 0 to $100 \mathrm{mM}$ for most of the compositions except in the presence of $\mathrm{Nal}$, in this case working concentration was 0 to $1 \mathrm{mM}$.

\section{Halide Anion Specificity for G2, G4, and G6 is Evident in their Surface Activity}

Dependence of surface tension on the concentration of a surfactant yields adsorption isotherms revealing characteristic parameters such as critical micelle concentration (CMC), air/water partitioning coefficient $\left(K_{\mathrm{aw}}\right)$, and molecular cross sectional area $\left(A_{S}\right)$. For these cationic gemini surfactants, however, the adsorption kinetics of surfactants at lower concentrations (0 to $1 \mathrm{mM}$ ) was exceedingly slow, and equilibrium was not reached even after $4.5 \mathrm{~h}$ in repeated measurements. For even longer measurement times solvent under evaporation proved too significant for us to reach equilibrium. Hence, any estimates on CMC or molecular area we could present would be highly dependent on the timepoint of measurement. In contrast, the maximal surface pressure of surfactants in the presence of different salts extracted from adsorption isotherms was nearly constant after $1.5 \mathrm{~h}$.

Adsorption isotherms of G2, G4, and G6 were measured in the presence of $\mathrm{Na}^{+}$salts of $\mathrm{F}^{-}, \mathrm{Cl}^{-}, \mathrm{Br}^{-}$, 


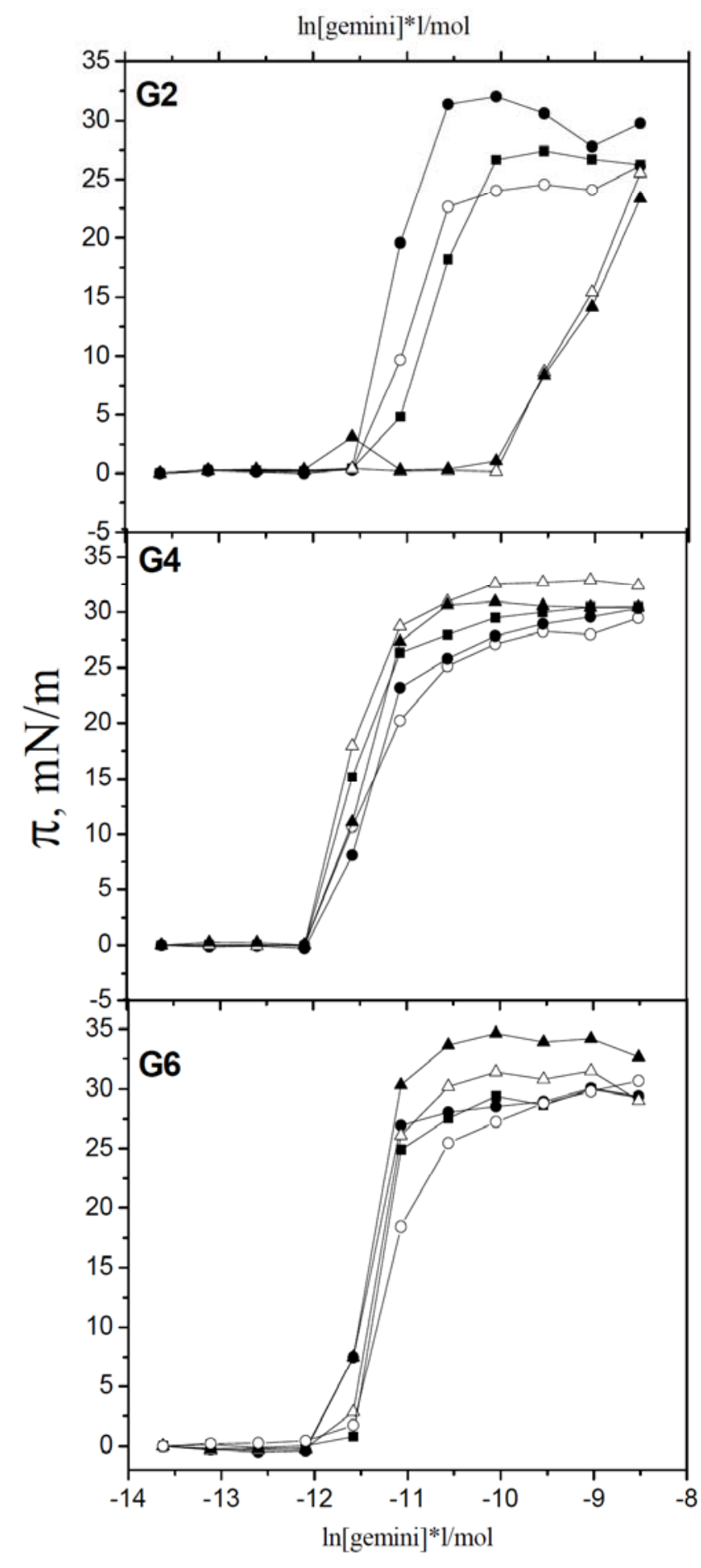

Figure 2: Surface pressure isotherms for G2, G4, and G6 (as indicated) in water (-), $0.1 \mathrm{mM} \mathrm{NaF}($,), $\mathrm{NaCl}(!), \mathrm{NaBr}(8)$, and $\mathrm{Nal}(7)$.

and $\mathrm{I}^{-}$(Figure 2). For G2 maximum value of surface pressure $\left(\pi_{\max }\right)$ was higher in the presence of $\mathrm{NaF}$ and $\mathrm{NaCl}$. Analogously, for $\mathrm{G} 4$ and $\mathrm{G} 6$ highest values of $\pi_{\max }$ were observed for $\mathrm{NaBr}$ and $\mathrm{Nal}$ (Figure 2), respectively. Dependence of $\pi_{\max }$ for $\mathrm{G} 2, \mathrm{G} 4$, and $\mathrm{G} 6$ on counterion diameter at low [salt] $=0.1 \mathrm{mM}$ was clearly seen (Figure 3). Similar trend was observed at higher salt concentrations, but some of the surfactantsalt combinations precipitated at high salt concentrations, and hence we chose only low salt concentrations for comparison. Accordingly, maximum surface pressure, $\pi_{\max }$ and hence presumably highest affinity for G2, G4, and G6 was observed with fluoride and/or chloride, bromide, and iodide, respectively. The same ion specificity was evident in the CMC of surfactants at higher salt concentrations, with shifts to elevated values evident for ions as large or larger than chloride, bromide, or iodide, for G2, G4, and G6, respectively (data not shown).

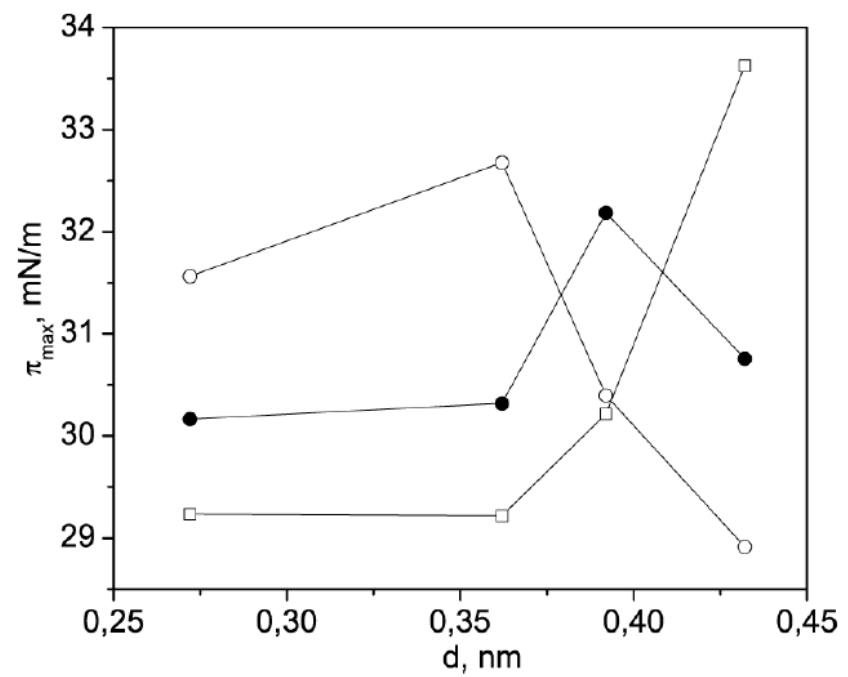

Figure 3: Variation of $\pi_{\max }$ measured in [salt] $=0.1 \mathrm{mM}$ as a function of counterion diameter $\mathrm{d}$, corresponding from left to right to $\mathrm{F}^{-}, \mathrm{Cl}^{-}, \mathrm{Br}^{-}$, and I' for $\mathrm{G} 2(-), \mathrm{G} 4($,$) , and \mathrm{G} 6(\forall)$.

\section{Effects of Temperature and Counterion on the Self- Assembly of G2, G4, and G6}

DLS of three geminis, G2, G4, and G6 in the absence of salt gave average diameters, $Z_{a v}$ of 221 , 167 , and $164 \mathrm{~nm}$, respectively, indicating the presence of small vesicles or clusters of micelles. A representative figure showing different transition phases observed during variation of $Z_{a v}$ with temperature for $1 \mathrm{mM} \mathrm{G} 4$ in the presence of $100 \mathrm{mM}$ $\mathrm{NaCl}$ (Figure 4, panel A) and $\mathrm{NaBr}$ (Figure 4, panel B), respectively. Complete data set for variation of $Z_{a v}$ with temperature for different salt concentrations can be found in supplementary materials (Supporting Material, Figures S1-S4).

For $\mathrm{G} 2$ dispersions at [salt] $=0 \mathrm{mM} \mathrm{Z}_{\mathrm{av}}$ increased linearly with temperature up to $30{ }^{\circ} \mathrm{C}$, with a sharp decrease at $\mathrm{T}=45^{\circ} \mathrm{C}$ (Supporting Material, Figure S1, panel A). Temperature scans of aqueous dispersions 

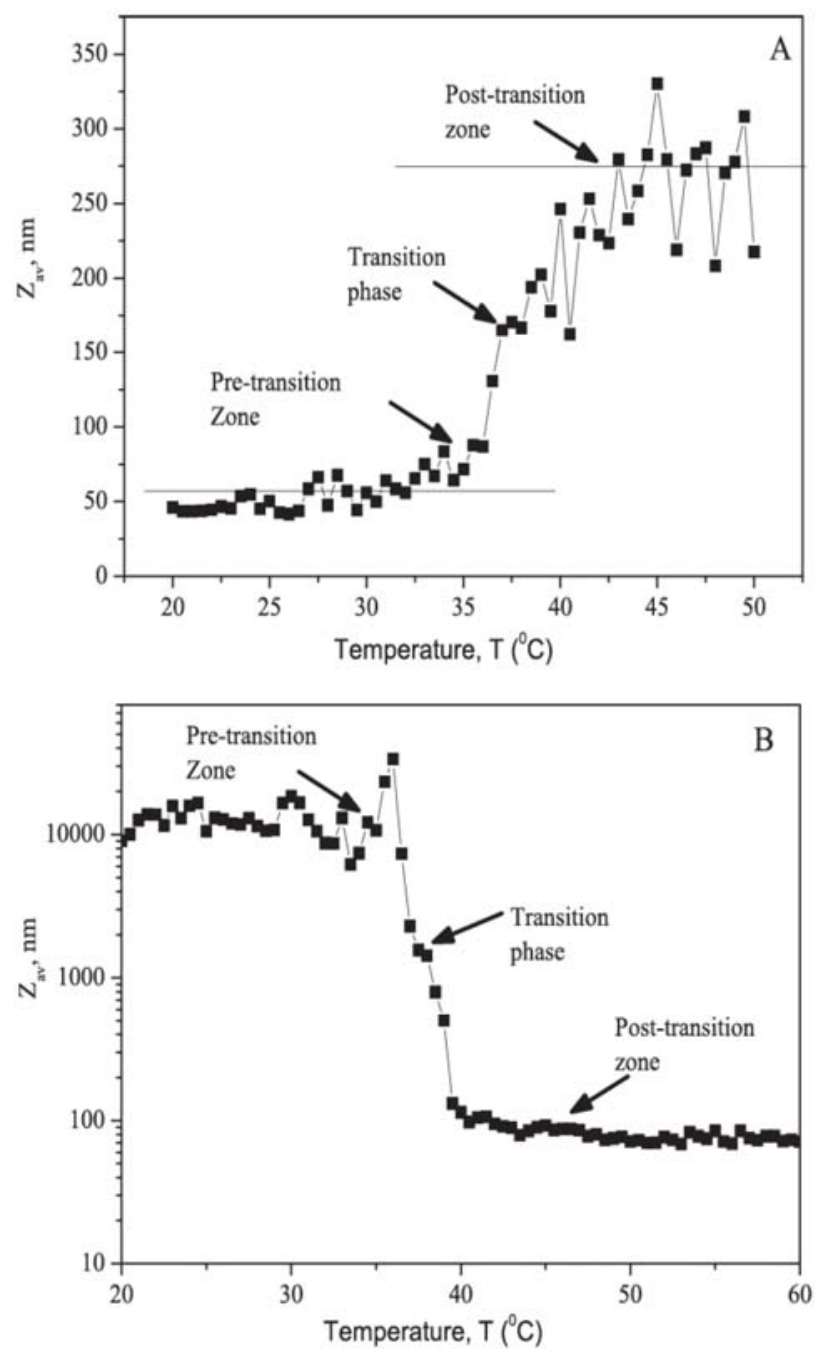

Figure 4: $A$ representative figure showing variation of $Z_{a v}$ with temperature highlighting different transition phases for 1 $\mathrm{mM} \mathrm{G} 4$ in the presence of $100 \mathrm{mM} \mathrm{NaCl}$ (panel A) and 100 $\mathrm{mM} \mathrm{NaBr}$ (panel B), respectively.

of $\mathrm{G} 4$ at [salt] $=0 \mathrm{mM}$ showed a progressive increase in $Z_{\mathrm{av}}$ from 165 to $700 \mathrm{~nm}$ (Supporting Material, Figure S1, panel B). G6 in the absence of salt and at room temperature had $Z_{\mathrm{av}} \approx 164 \mathrm{~nm}$, while with temperature $Z_{a v}$ increased to $2200 \mathrm{~nm}$ measured at $40{ }^{\circ} \mathrm{C}$ (Supporting Material, Figure S1, panel C). Subsequently, variation of $Z_{a v}$ with varying temperature was recorded for $\mathrm{G} 2, \mathrm{G} 4$, and $\mathrm{G} 6$ in the presence of different salt concentrations and $Z_{\mathrm{av}}$ was calculated for both pre and post transition periods and plotted vs [NaCl] (Figure 5, panel A), [NaBr] (Figure 5, panel B), and [Nal] (Figure 5, panel C), respectively.

Most interesting changes in $Z_{a v}$ were observed for G2, G4, and $\mathrm{G} 6$ in the presence of $\mathrm{NaCl}, \mathrm{NaBr}$, and $\mathrm{Nal}$, respectively, as the difference between pre and post transition $Z_{a v}$ was quite pronounced indicating strong interaction of counter ion $\mathrm{Cl}^{-}, \mathrm{Br}^{-}$, and I' with two,
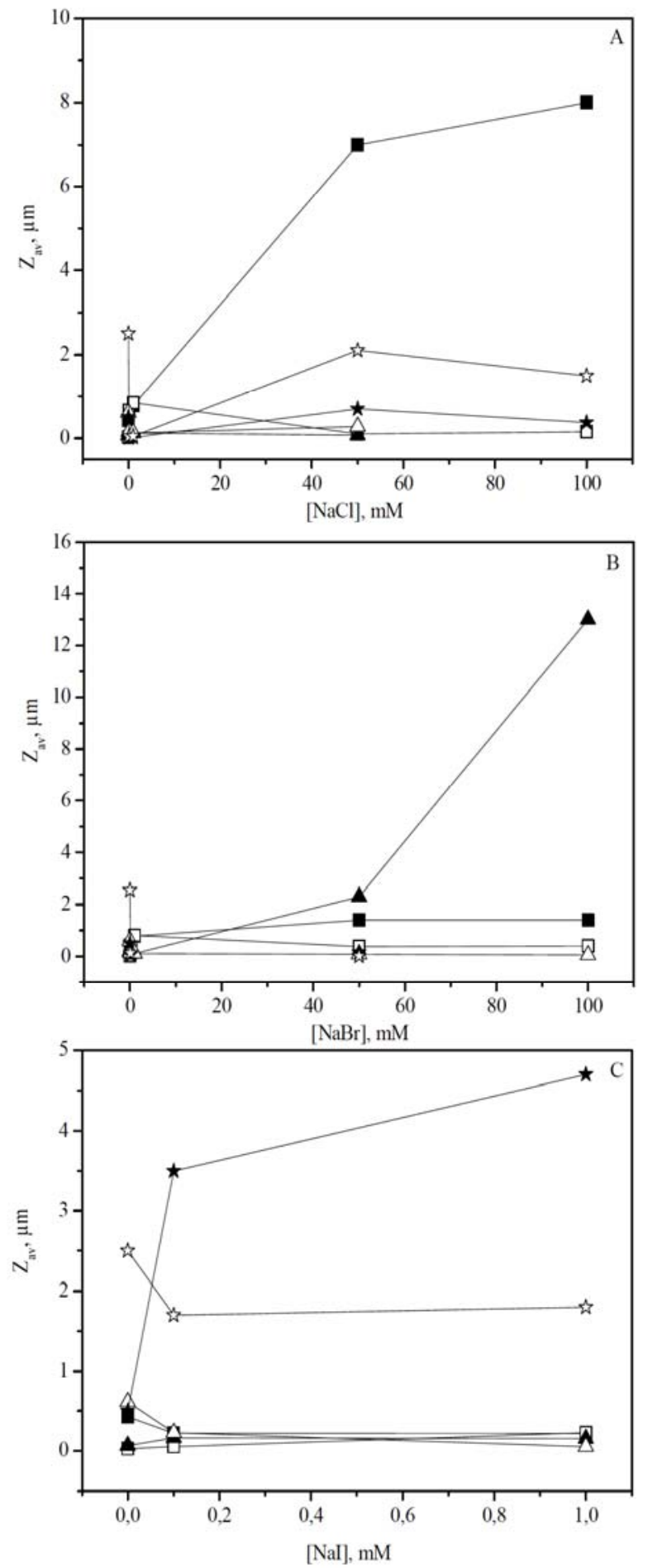

Figure 5: Pre (open symbols) and post transition (filled symbols) $Z_{a v}$ for $\mathrm{G} 2$ in $100 \mathrm{mM} \mathrm{NaCl}$, for G4 in $100 \mathrm{mM} \mathrm{NaBr}$, and for $\mathrm{G} 6$ in $1 \mathrm{mM} \mathrm{Nal}$ was calculated and plotted as a function of [salt]. Accordingly, variation of pre and post transition $Z_{\mathrm{av}}$ for $\mathrm{G} 2(\square, \boldsymbol{\square}), \mathrm{G} 4,(\Delta, \mathbf{\Delta})$, and $\mathrm{G} 6(\boldsymbol{\star})$ in the presence of $\mathrm{NaCl}$ (panel A), $\mathrm{NaBr}$ (panel B), and $\mathrm{Nal}$ (panel C). Larger difference in the pre and post transition $Z_{a v}$ indicates higher affinity of gemini with counterion.

four, and six carbon spacer of G2, G4, and G6, respectively. 
Transition temperatures obtained from DLS data were comparable to main phase transition temperature $\left(T_{m}\right)$ observed in DSC scans. Accordingly, for aqueous dispersions of $\mathrm{G} 2$ three sharp endotherms following a minor peak at $\approx 36^{\circ} \mathrm{C}$ were observed between 42 to 45 ${ }^{\circ} \mathrm{C}$ (Figure 6, inset of panel A) whereas no endotherms were observed for dispersions of G4 and G6 in pure water. For $\mathrm{G} 2$ with 0.1 and $1 \mathrm{mM} \mathrm{NaCl}$ no significant shift in the endotherms was observed, however, with $50 \mathrm{mM} \mathrm{NaCl}$, smaller peaks at 32 and $36{ }^{\circ} \mathrm{C}$, preceded a large endotherm at $\approx 41{ }^{\circ} \mathrm{C}$. The former smaller peaks were absent at $[\mathrm{NaCl}]=100 \mathrm{mM}$ while major peak remained. In the presence of 0.1 and $1 \mathrm{mM} \mathrm{NaCl}$ no endotherms were observed for aqueous dispersions of $\mathrm{G} 4$. But in $50 \mathrm{mM} \mathrm{NaCl}$ endotherm with $\mathrm{T}_{\mathrm{m}}$ at $\approx 24$ ${ }^{\circ} \mathrm{C}$ became evident for $\mathrm{G} 4$, further increase in [salt] had no significant effect (Figure 6, panel B). For G6 up to $100 \mathrm{mM} \mathrm{NaCl}$ no endotherms were observed.
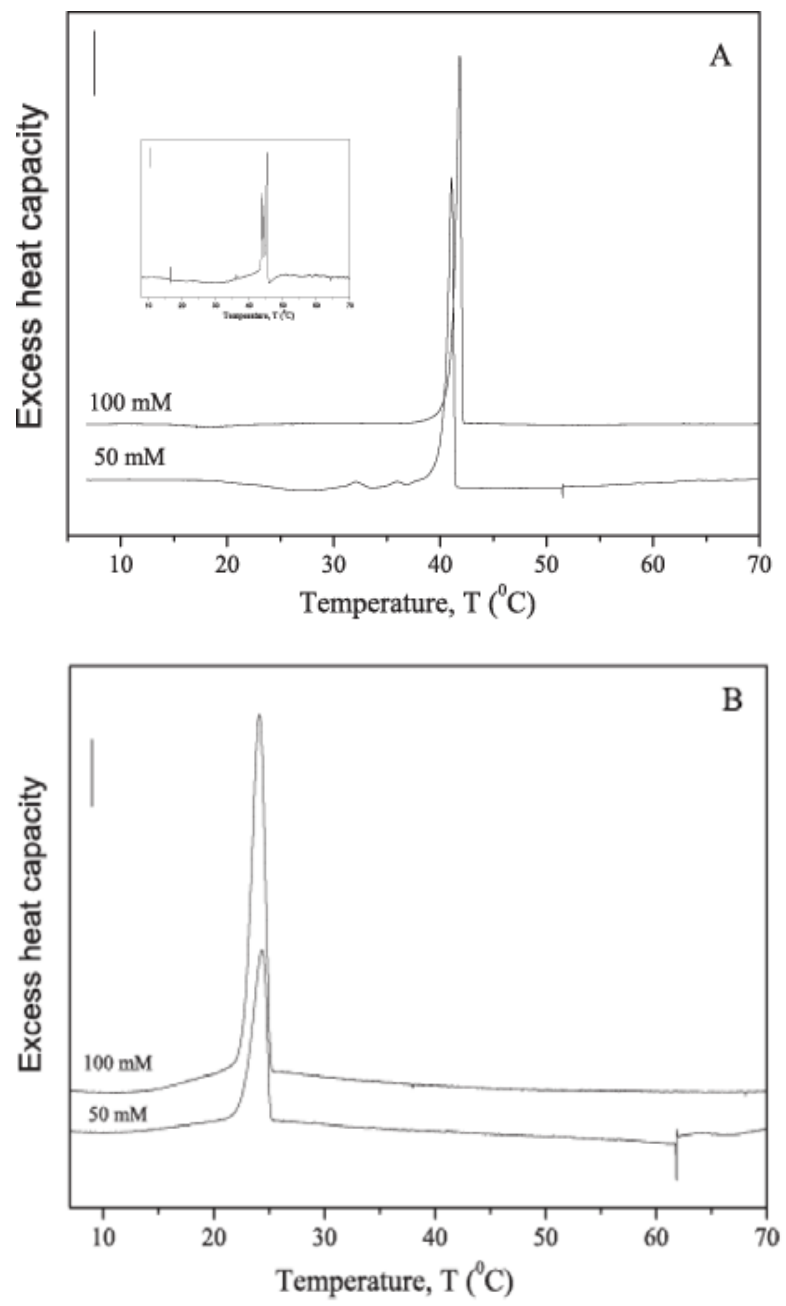

Figure 6: DSC traces of G2 (panel A), and G4 (panel B) in the presence of indicated $[\mathrm{NaCl}$. Dispersions of $\mathrm{G} 2$ in pure water exhibited a reproducible pattern of multiple endotherms (inset of panel A), whereas G4 in pure water did not exhibit any peak. No peak was observed for G6 either in the absence or presence of $\mathrm{NaCl}$.
Variation of $Z_{a v}$ with temperature for $G 2$ in the presence of 0.1 and $1 \mathrm{mM} \mathrm{NaBr}$ were identical to that in pure water and no endotherms were observed in DSC. In $50 \mathrm{mM} \mathrm{NaBr} Z_{\mathrm{av}}$ for $\mathrm{G} 2$ increased with temperature reaching a maximum of $1500 \mathrm{~nm}$ at $\mathrm{T}=43$ ${ }^{\circ} \mathrm{C}$, followed by a decrease in $\mathrm{Z}_{\mathrm{av}}$ observed at $\approx 45{ }^{\circ} \mathrm{C}$ (Supporting Material, Figure S3, panel A). This transition is visible in DSC scans with sharp endotherm appearing at $\approx 45{ }^{\circ} \mathrm{C}$ (Figure 7 , panel A). No endotherms were observed for aqueous dispersions of G4 in the presence of 0.1 and $1.0 \mathrm{mM} \mathrm{NaBr}$. However, DSC scans showed endotherm with $\mathrm{T}_{\mathrm{m}}$ at $\approx 35.1$ and $36.6{ }^{\circ} \mathrm{C}$ for $\mathrm{G} 4$ in 50 and $100 \mathrm{mM} \mathrm{NaBr}$, respectively

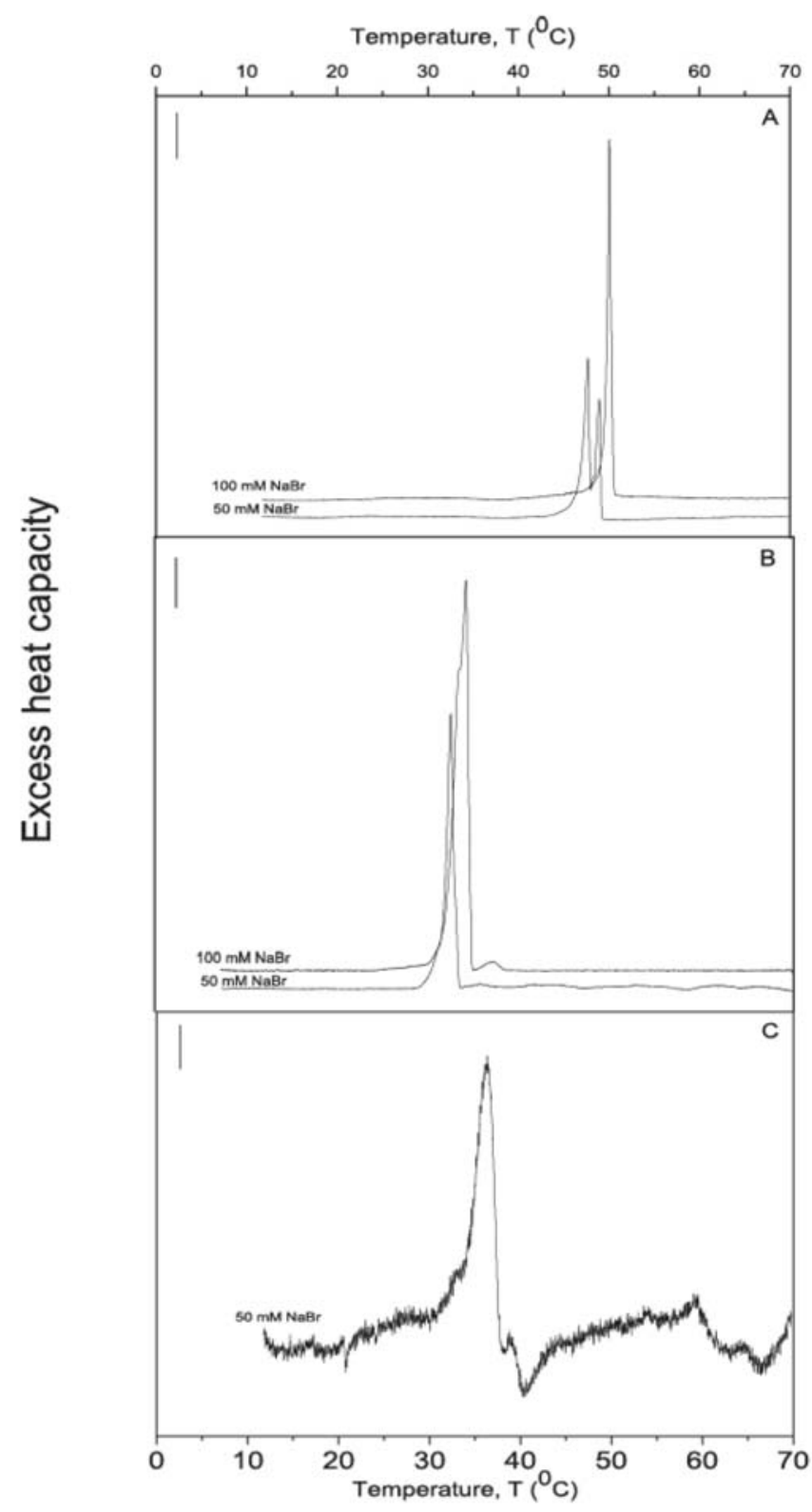

Figure 7: DSC traces of G2 (panel A), G4 (panel B), and G6 (panel $\mathbf{C}$ ) in the presence of indicated [ $\mathrm{NaBr}]$. No endotherm was observed for G6 in the presence of $100 \mathrm{mM} \mathrm{NaBr}$. 
(Figure 7, panel B). Values of $\mathrm{T}_{\mathrm{m}}$ for $\mathrm{G} 4$ in the presence of $\mathrm{NaBr}$ were higher compared to $\mathrm{NaCl}$ indicating tighter packing. No endotherms were observed for aqueous dispersions of $\mathrm{G} 6$ in the presence of 0.1 and $1.0 \mathrm{mM} \mathrm{NaBr}$. In $50 \mathrm{mM} \mathrm{NaBr}$ dispersions of $\mathrm{G} 6$ have $\mathrm{Z}_{\mathrm{av}} \approx 80 \mathrm{~nm}$ at $20^{\circ} \mathrm{C}$, with increasing temperature augmenting $Z_{\mathrm{av}}$ up to $180 \mathrm{~nm}$ at $38^{\circ} \mathrm{C}$, followed by a drop result to $Z_{\mathrm{av}} \approx 20 \mathrm{~nm}$ at $41^{\circ} \mathrm{C}$ (Supporting Material, Figure S3, panel C). In $50 \mathrm{mM}$ $\mathrm{NaBr}$ DSC scans showed an endotherm at $35{ }^{\circ} \mathrm{C}$ (Figure 7, panel C). Determination of $Z_{a v}$ and DSC scans was not possible to record due to precipitation of G6 in $100 \mathrm{mM} \mathrm{NaBr}$.

DLS and DSC scans of G2 in the presence of 0.1 $\mathrm{mM}$ Nal exhibited transitions at 48 and $49{ }^{\circ} \mathrm{C}$ (Supporting Material, Figure S4, panel A), respectively, preceded by an additional minor peak at $38{ }^{\circ} \mathrm{C}$ (Supporting Material, Figure S5, panel A). In the presence of $1 \mathrm{mM} \mathrm{Nal}$ a sharp endotherm at $52{ }^{\circ} \mathrm{C}$ was observed (Supporting Material, Figure S5, panel A). No transition phase either in DSC or DLS was observed for G4 with $0.1 \mathrm{mM} \mathrm{Nal}$ whereas in $1 \mathrm{mM} \mathrm{Nal} \mathrm{DSC} \mathrm{scan}$ for $\mathrm{G} 4$ did show a broad endotherm $\approx 30^{\circ} \mathrm{C}$. In $0.1 \mathrm{mM}$ $\mathrm{Nal}$ aqueous dispersions of $\mathrm{G} 6$ resulted in an increase in $Z_{a v}$ up to $3000 \mathrm{~nm}$ with a decrease in $Z_{a v}$ around 39 ${ }^{\circ} \mathrm{C}$. In $[\mathrm{Nal}]=1 \mathrm{mM} \mathrm{Z}_{\mathrm{av}}$ increased to $4800 \mathrm{~nm}$ (Supporting Material, Figure S4, panel C). No endotherms were observed by DSC for G6 dispersions in the presence of $\mathrm{Nal}$. The above findings are compiled into Table 1.

In brief, thermal phase behavior and maximum in $Z_{a v}$ for three cationic geminis $G 2, G 4$, and G6 showed a strong dependence on the counterion. More specifically, maximum change in pre and post transition $Z_{a v}$ for $\mathrm{G} 2$ was observed in $100 \mathrm{mM} \mathrm{NaCl}$ (Figure 5, panel A), for G4 in $100 \mathrm{mM} \mathrm{NaBr}$ (Figure 5, panel B), and $\mathrm{G} 6$ in $1 \mathrm{mM} \mathrm{Nal}$ (Figure 5, panel C)

\section{Microscopy of Aggregates Formed by G2, G4, and G6}

DLS revealed presence of large aggregates in the presence of salt for G2 and G4. To obtain better insight into the morphology of these aggregates, we imaged some of the large aggregates by optical microscopy. In particular, aqueous dispersions of G2, G4, and G6 with maximum increase in $Z_{a v}$ at particular [salt] were observed under optical microscope with temperature increased from 20 to $50{ }^{\circ} \mathrm{C}$. Aggregates of varying morphologies were observed.

Dispersions of G4 in $100 \mathrm{mM} \mathrm{NaBr}$ appeared as free floating aggregates close to the bottom of the observation chamber at $25{ }^{\circ} \mathrm{C}$ (Figure 8, panel A). Changes in morphologies of these aggregates were observed upon increasing the temperature to $30{ }^{\circ} \mathrm{C}$. Occasionally, also large spherical vesicles were

Table 1: Maximum Apparent Values for $Z_{a v}$ (in $\mathrm{nm}$ ) and $T_{m}$ (Obtained from DSC) for G2, G4, and G6 in the Presence of Indicated Concentrations of $\mathrm{NaCl}, \mathrm{NaBr}$, and $\mathrm{Nal}$, Respectively

\begin{tabular}{|c|c|c|c|c|c|c|}
\hline \multirow[b]{2}{*}{$\mathrm{NaCl}, \mathrm{mM}$} & \multicolumn{2}{|c|}{ G2 } & \multicolumn{2}{|c|}{ G4 } & \multicolumn{2}{|c|}{ G6 } \\
\hline & $\mathrm{Z}_{\mathrm{av}}$ & $T_{m}$ & $\mathrm{Z}_{\mathrm{av}}$ & $\mathbf{T}_{\mathrm{m}}$ & $\mathrm{Z}_{\mathrm{av}}$ & $\mathbf{T}_{\mathrm{m}}$ \\
\hline 0 & 221 & 45.3 & 700 & $\mathrm{NP}^{*}$ & 2000 & NP \\
\hline 0.1 & 800 & 45.1 & 155 & $\mathrm{NP}$ & 100 & NP \\
\hline 1.0 & 900 & 45.0 & 130 & NP & 200 & NP \\
\hline 50 & 7000 & 41.1 & 200 & 24.4 & 1000 & NP \\
\hline 100 & 8000 & 41.2 & 150 & 24.1 & 800 & NP \\
\hline \multicolumn{7}{|l|}{$\mathrm{NaBr}, \mathrm{mM}$} \\
\hline 0.1 & 145 & NP & 130 & NP & 200 & NP \\
\hline 1.0 & 850 & NP & 150 & NP & & NP \\
\hline 50 & 1500 & 47.0 & 3000 & 35.0 & 200 & 35.0 \\
\hline 100 & 2000 & 50.0 & 10000 & 36.0 & 150 & $\mathrm{PS}^{*}$ \\
\hline \multicolumn{7}{|l|}{ Nal, mM } \\
\hline 0.1 & 250 & 45.0 & 150 & 30.0 & 3500 & NP \\
\hline 1 & 300 & 50.0 & 150 & 30.0 & 4800 & NP \\
\hline
\end{tabular}

$\mathrm{NP}^{*}=$ No peak in DSC was observed. $\mathrm{PS}^{*}=$ Poor solubility. 


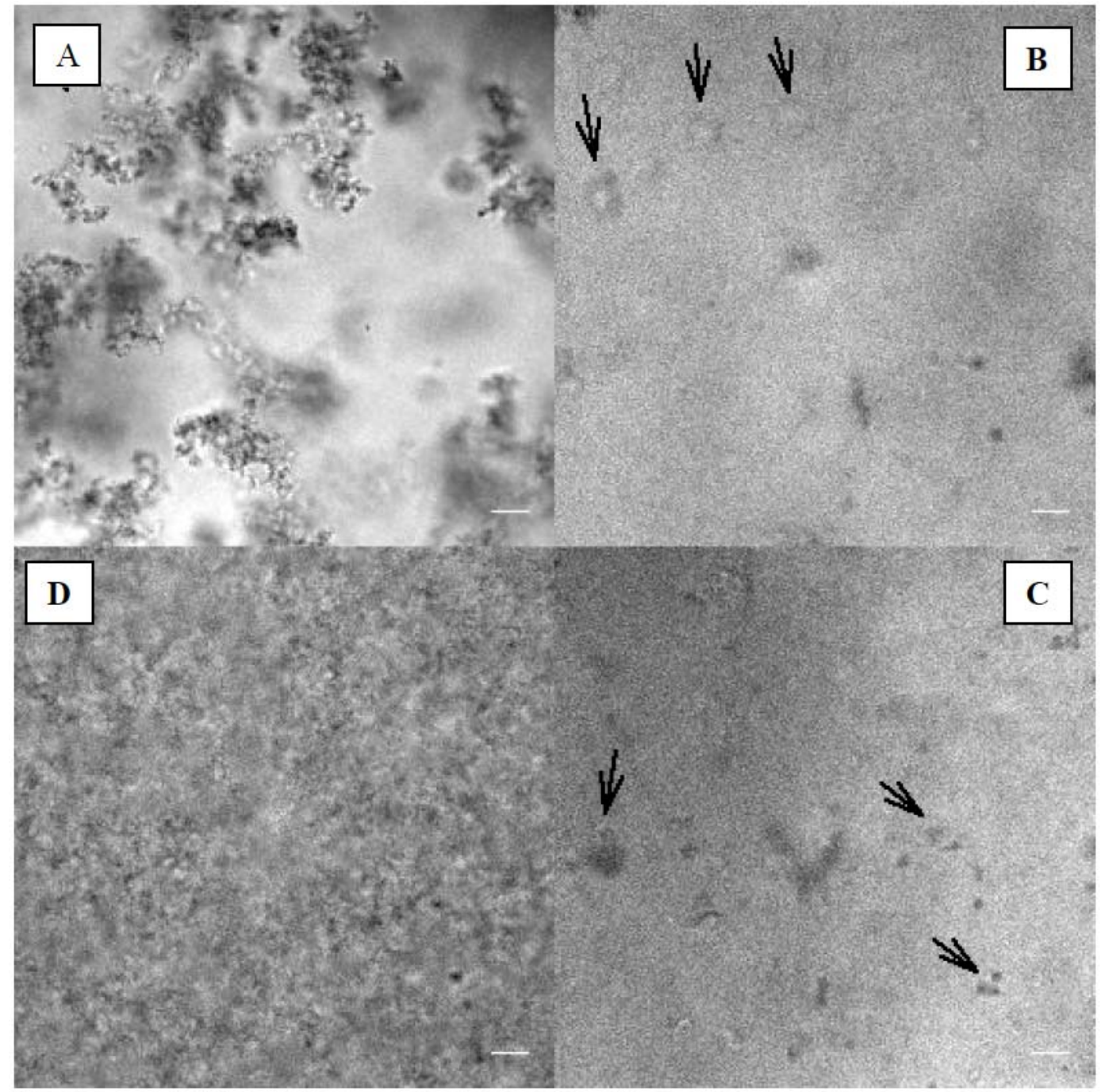

Figure 8: Visualization of aggregates formed by $\mathrm{G} 2$ and $\mathrm{G} 4$ in the presence of $100 \mathrm{mM} \mathrm{NaCl}$ and $\mathrm{NaBr}$ at different temperatures using optical microscopy. G4 in the presence of $100 \mathrm{mM} \mathrm{NaBr}$ at $25^{\circ} \mathrm{C}$ (panel A), however, at $29^{\circ} \mathrm{C}$ few large vesicles were seen (panel B), further heating to $40^{\circ} \mathrm{C}$ leads to disappearance of larger vesicles yet smaller micelles were observed (panel C). Dense aggregates were observed for $\mathrm{G} 2$ in the presence $100 \mathrm{mM} \mathrm{NaCl}$, morphology of these aggregates didn't changed with increase in temperature (panel D).

observed together with dense aggregates at $\approx 29{ }^{\circ} \mathrm{C}$ (Figure 8, panel B). With increasing temperature up to $40{ }^{\circ} \mathrm{C}$ larger vesicles disappeared with the appearance of smaller vesicles (Figure 8, panel C). In $100 \mathrm{mM} \mathrm{NaCl}$ the formation of dense aggregates by $\mathrm{G} 2$ was seen (Figure 8, panel D). Their morphology did not change within the temperature range studied. For G6 in the presence of $\mathrm{Nal}$ no dense aggregates were observed. Overall size of the free floating aggregates formed by G6 (with Nal) was smaller (data not shown) compared to $\mathrm{G} 2$ (with $\mathrm{NaCl}$ ) and $\mathrm{G} 4$ (with $\mathrm{NaBr}$ ).

\section{Effect of Temperature and Ammonium Salts on the Self-Assembly of G2, G4, and G6}

In the commensurate lattice model not only identity of counterion but also identity of co-ion is expected to affect interactions of salt with surfactant. To check importance of the salt cation $Z_{a v}$ was measured also as a function of temperature for $\mathrm{G} 2, \mathrm{G} 4$, and $\mathrm{G} 6$ in the presence of $\mathrm{NH}_{4} \mathrm{Cl}, \mathrm{NH}_{4} \mathrm{Br}$, and $\mathrm{NH}_{4}$ l respectively. Most significant changes for $\mathrm{G} 2$ and $\mathrm{G} 4$ in the presence of $\mathrm{NH}_{4} \mathrm{Cl}$ and $\mathrm{NH}_{4} \mathrm{Br}$ were observed at concentrations $\geq$ $50 \mathrm{mM}$. Accordingly, in $100 \mathrm{mM} \mathrm{NH}_{4} \mathrm{Cl}$ there was an increase in $Z_{\mathrm{av}}$ for $\mathrm{G} 2$ up to $2500 \mathrm{~nm}$, with a transition at $41^{\circ} \mathrm{C}$ (Figure 9, panel $\mathbf{A}$ ). This increase in $Z_{a v}$ was significantly less compared to the aqueous dispersions of $\mathrm{G} 2$ in the presence of $\mathrm{NaCl}$. In $50 \mathrm{mM} \mathrm{NH}_{4} \mathrm{Cl}$ a single peak at $\mathrm{T}_{\mathrm{m}} \approx 41.2{ }^{\circ} \mathrm{C}$ was observed in DSC and further increase to $100 \mathrm{mM} \mathrm{NH}_{4} \mathrm{Cl}$ did not produce significant changes in $\mathrm{T}_{\mathrm{m}}$ (data not shown). For $\mathrm{G} 4$ in $50 \mathrm{mM} \mathrm{NH}_{4} \mathrm{Br}$ values of $Z_{\mathrm{av}}$ remain unchanged up to 30 ${ }^{\circ} \mathrm{C}$, following an increase in $Z_{\text {av }}$ up to $800 \mathrm{~nm}$ with a 
transition at $35{ }^{\circ} \mathrm{C}$. In $100 \mathrm{mM} \mathrm{NH}_{4} \mathrm{Br} \mathrm{Z}_{\mathrm{av}}$ increased from beginning of the temperature scan with a maximum at $1000 \mathrm{~nm}$ followed by a transition around $36{ }^{\circ} \mathrm{C}$ (Figure 9, panel B). DSC scans for aqueous dispersions of $\mathrm{G} 4$ in the presence of 50 and $100 \mathrm{mM}$ $\mathrm{NH}_{4} \mathrm{Br}$ resulted in $\mathrm{T}_{\mathrm{m}}$ at $\approx 35.1$ and $36.5{ }^{\circ} \mathrm{C}$, respectively (data not shown).

Aqueous dispersions of $\mathrm{G} 6$ in the presence of 0.1 $\mathrm{mM} \mathrm{NH}_{4}$ l resulted in slight increase in $\mathrm{Z}_{\mathrm{av}}$ over the whole temperature range, however, it was not possible to record DLS/DSC scans at higher concentration of $\mathrm{NH}_{4} \mathrm{I}$ due to poor solubility and immediate precipitation of G6.
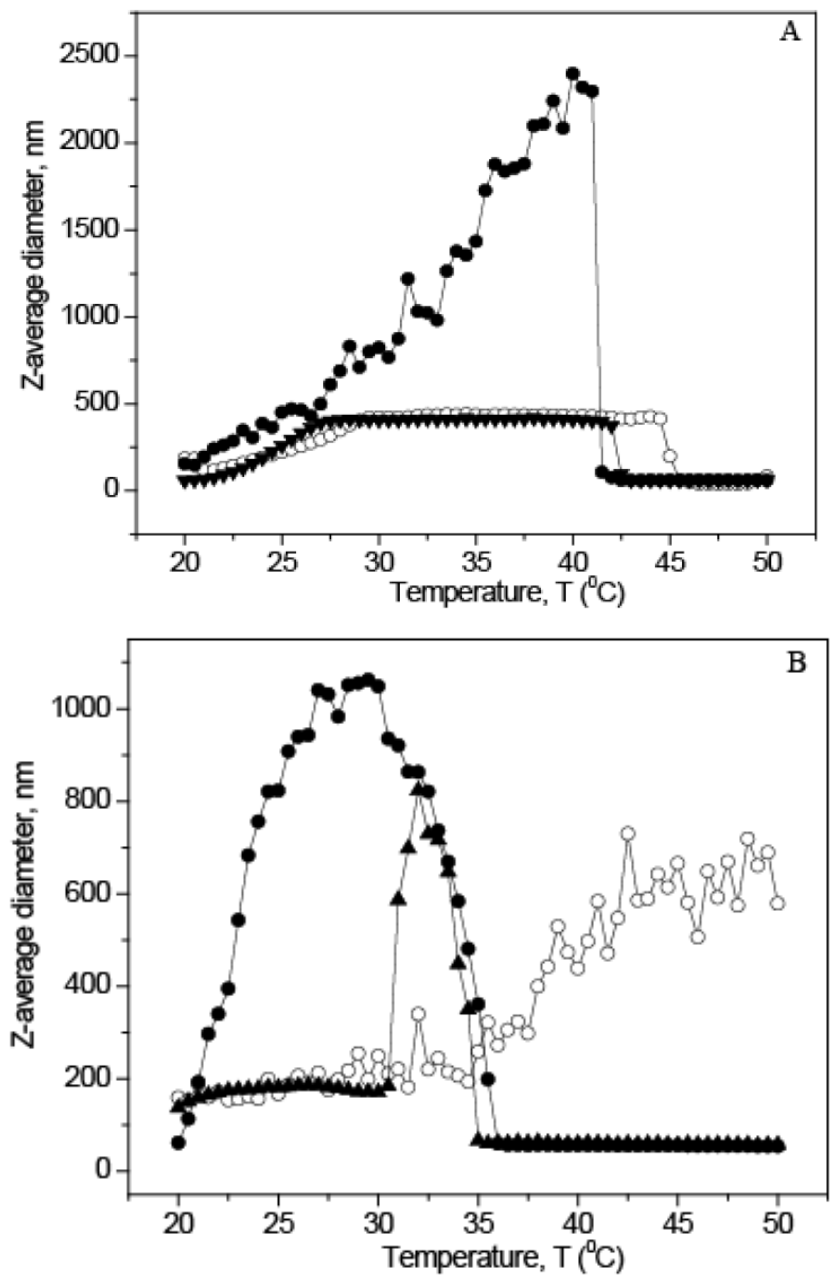

Figure 9: Variation of Z-average diameter vs temperature for one $\mathrm{mM} \mathrm{G} 2$ (panel A) in the presence of $\left[\mathrm{NH}_{4} \mathrm{Cl}\right]=0(-), 50$ $(B)$, and $100 \mathrm{mM}(\bullet)$ and for one $\mathrm{mM} \mathrm{G} 4$ (panel $\mathbf{B}$ ) in the presence of $\left[\mathrm{NH}_{4} \mathrm{Br}\right]=0(-), 50(\mathrm{~B})$, and $100 \mathrm{mM}(\bullet)$.

\section{DISCUSSION}

Common effect of salt is to increase the melting temperature of charged amphiphiles. In gel-like phase headgroups are packed closer than in the fluid phase and when unscreened there is a strong repulsion between headgroups, favoring fluid phase, decreasing $T_{m}$. In contrast, presence of $\mathrm{NaCl}$ decreases $\mathrm{T}_{\mathrm{m}}$ for aqueous dispersions of G2. One possibility is that in the absence of salt G2 is in interdigitated phase with a higher melting temperature [22] and that salt induced decrease in charge repulsion leads to the formation of a non-interdigitated state. The other possibility is that $\mathrm{Cl}^{-}$ions binds with higher affinity to fluid phase G2, possibly requiring a headgroup conformation which is incompatible with gel phase packing. Addition of salt also results in disappearance of multiple components in the heat capacity scan with appearance of a single endotherm at $41^{\circ} \mathrm{C}$. The presence of multiple peaks in endotherms may derive from either different G2 aggregates morphologies (polymorphs) present in lipid membranes or from interdigitated $\rightarrow$ non-interdigitated transition followed by a chain melting transition. It seems that overall stability of assembly of G2 decreases in the presence of salt. This unusal behavior was further substantiated by measuring size of aggregates formed by $\mathrm{G} 2$ in the absence as well as presence of salt. It appears that within a particular temperature range and $[\mathrm{NaCl}]$ some kind of ioncounterion lattice is formed, which causes a large $Z_{a v}$ and it is thermally stable up to $40^{\circ} \mathrm{C}$. High specificity of G2 for $\mathrm{Cl}^{-}$was observed also in surface activity measurements (Figures 2 and 3). Transition temperatures obtained for G2 from DLS and DSC measurements are in good agreement with each other. Along similar lines, we have observed that gemini surfactant RR-1 interacts avidly with $\mathrm{NaCl}$ forming crystalline aggregates and suggesting specific interactions between RR-1 and $\mathrm{Cl}^{-}$. We proposed that dicationic headgroup acts as a nucleating surface for $\mathrm{Cl}^{-}$counterions to form a planar, pseudocrystalline lattice commensurate with 111-facet for $\mathrm{Cl}^{-}$in a $\mathrm{NaCl}$ crystal [23]. In the present study, increase in spacer length results in increased distance between two headgroups preventing gel-like packing of surfactant molecules hence lacking a sharp melting transition with an observable enthalpy for aqueous dispersions of G4 and G6. However, 50 and $100 \mathrm{mM}$ of $\mathrm{NaCl}$ was sufficient to screen highly charged headgroups of dicationic gemini, G4 and G6, leading to effective packing of surfactant molecules yielding endotherms at 24.4 and $30.4{ }^{\circ} \mathrm{C}$, respectively. The order of stability in the presence of $\mathrm{NaCl}$ as reflected by $\mathrm{T}_{\mathrm{m}}$ values from DSC was G2 > G6 > G4. Greater stability of G6 dispersions compared to $\mathrm{G} 4$ is interesting considering the fact that $\mathrm{G} 6$ has a longer spacer. Unusual thermal phase behavior (from DSC) and different kind of 
aggregates formed (from DLS) by aqueous dispersions of G2, G4, and G6 in the absence as well as presence of [ $\mathrm{NaCl}]$ prompted us to study effects of counter ions such as bromide and iodide. Interestingly, increase in $\mathrm{T}_{\mathrm{m}}$ for dispersions of $\mathrm{G} 2$ in the presence of both $\mathrm{NaBr}$ and Nal could indicate absence of interdigitated phase (Figure 7. panel A and Supporting Material, Figure S5, panel A), which was observed in the presence of $\mathrm{NaCl}$. For dispersions of $\mathrm{G} 4$, an increase of $\approx 10{ }^{\circ} \mathrm{C}$ in $\mathrm{T}_{\mathrm{m}}$ along with appearance of large aggregates indicates higher stability as well as high affinity of $\mathrm{G} 4$ for $\mathrm{Br}^{-}$as a counterion. Upon comparison with $\mathrm{I}^{-}$an increase by 4 ${ }^{\circ} \mathrm{C}$ of $\mathrm{T}_{\mathrm{m}}$ and increase in $\mathrm{Z}_{\mathrm{av}}$ upto $\approx 150 \mathrm{~nm}$ were observed. Similarly, high affinity of $G 6$ for $I$ as a counterion was observed whereas weaker interactions were observed for $\mathrm{Cl}^{-}$and $\mathrm{Br}^{-}$. The effects of different counterions was studied by measuring surface pressure as a function of surfactant concentration, yielding CMCs. We observed that spacer length controls the specificity for size of counter ion. For instance, G2 prefers fluoride and/or chloride, whereas G4 and G6 have high specificity for bromide and iodide as evidenced by higher values of $\pi$ (at [salt] $=0.1 \mathrm{mM}$ ) and high CMCs (at [salt] $>20 \mathrm{mM}$ ).

We observed formation of dense aggregates for dispersions of $\mathrm{G} 2$ in $\mathrm{NaCl}$ (Figure 8, panel D) and large aggregates for $\mathrm{G} 4$ in $\mathrm{NaBr}$ (Figure 8, panels A \& B). These aggregates of different morphologies could relate to headgroup-counterion hydration $[22,24]$ and molecular geometry of effective shapes of lipids controls 3-D phase behavior of lipid assemblies. This relationship is rationalized in terms of a packing parameter $(p=\mathrm{U} / \mathrm{al})$ and for formation of planar bilayers (as observed in giant vesicles) $p \approx 1$. For $p \approx 1$ there should be significant reduction in the headgroup area leading to lower values of a. However, no evidence for reduction in a was obtained from DSC, since upon increasing [salt] slight increase in $T_{m}$ was observed for these geminis indicating very little condensation of their aqueous dispersions. However, for dispersions of $\mathrm{G} 2$ in $\mathrm{NaCl}$ decrease in $\mathrm{T}_{\mathrm{m}}$ was observed indicating expansion of bilayer. Recently, we have shown that a cationic gemini lipid M-1 undergoes a sharp transition from micelles to giant vesicles depending on $\mathrm{NaCl}$ concentration and temperature [7]. The headgroups of $\mathrm{M}-1$ and $\mathrm{G} 2, \mathrm{G} 4$, and $\mathrm{G} 6$ are structurally very different with presence of chiral centers in the former. Hence extent of hydration of $\mathrm{M}-1$ is likely to be different from G2, G4, and G6 and presence of counter ion will substantially alter it further leading to formation of aggregates of different morphologies.
It seems that fixed distance between dicationic head group of G2, G4, and G6 acts as a surface template for counterions to organize in a controlled fashion. Taking into account molecular parameters such as the length of $-\left(\mathrm{CH}_{2}\right)_{2^{-}},-\left(\mathrm{CH}_{2}\right)_{4^{-}},-\left(\mathrm{CH}_{2}\right)_{6^{-}}$spacer in these geminis, ionic radii of different counterions with corresponding hydration shells it seems that $\mathrm{Cl}^{-}$would match with spacer length of G2. Analogously, $\mathrm{Br}^{-}$and $\mathrm{I}^{-}$fit better with G4 and G6, respectively. Another evidence for counter ion size mismatch with spacer length of G4 and G6 was observed from DLS and DSC in the presence of $\mathrm{NaCl}$. For instance, $\mathrm{NaCl}$ has no significant effect on $T_{m}$ for aqueous dispersions of G4 while an increase of only 2.7 degrees in $T_{m}$ for $G 6$ was observed with continuous decrease in $Z_{a v}$ indicating less specificity for $\mathrm{Cl}^{-}$counterion. Similar behavior was observed for $\mathrm{G} 2$ with $\mathrm{Br}^{-}$and $\mathrm{I}^{-}$and for $\mathrm{G} 6$ with $\mathrm{Cl}^{-}$and $\mathrm{Br}^{-}$as counterions. Upon replacing $\mathrm{Na}^{+}$with $\mathrm{NH}_{4}{ }^{+}$much smaller aggregates of $\mathrm{G} 2, \mathrm{G} 4$, and $\mathrm{G} 6$ were observed. A likely reason for this difference for G2/G4/G6 with $\mathrm{NaX}$ salts ( $X=$ chloride/bromide/iodide) could be that dicationic headgroup acts as a nucleating surface for counterions to form a planar, commensurate pseudocrystalline lattice corresponding to 111-facet for $\mathrm{NaX}$ crystals and associated with vesicle surface. Next to this layer of $\mathrm{X}^{-}$is $\mathrm{Na}^{+}$, followed by another layer of $\mathrm{X}^{-}$, and so on, thus promoting formation of large aggregates (evidenced by high $Z_{\mathrm{av}}$ ). The ion-counterion lattice would form only after a threshold [ $\mathrm{NaX}]$ reached at lower temperatures and is likely to be sensitive to the phase state of the nucleating membrane. More specifically, to efficiently initiate the formation of $\mathrm{NaX}$ crystal lattice, the amphiphiles in the bilayer would have to adapt their mean molecular area to lattice spacing. However, with $\mathrm{NH}_{4}{ }^{+} \mathrm{X}$, due to mismatching of cation size in the second layer (and on subsequent cation layers) over the $X^{-}$layer would not be commensurate. This less favorable arrangement of ioncounterions imparts strain and/or little stability to overall structure preventing lattice to grow on top of dicationic headgroup leading to formation of much smaller aggregates (evidenced by smaller $Z_{\mathrm{av}}$ ).

In the present study we show that specific length of an amphiphile is able to trap an ion of a particular size, for instance aqueous dispersions of $\mathrm{G} 2, \mathrm{G} 4$, and $\mathrm{G} 6$ are specific for $\mathrm{Cl}^{-}, \mathrm{Br}^{-}$, and $\mathrm{I}^{-}$, respectively. Hence, our results shows that by carefully designing the head group structure, it could be possible to generate amphiphiles which can be used to bind specific metal ions in solution, for purposes such as water purification and mineral enrichment. 


\section{CONCLUSIONS}

In continuation of our previous work [7], we have synthesized three cationic amphiphiles G2, G4, and G6 with alkyl spacers of two, four, and six carbon (Figure 1) and studied their behavior in the presence of varying concentrations of sodium salts of fluoride, chloride, bromide, and iodide using DLS, Langmuir balance, DSC, and microscopy addressing importance of spacer length of headgroup in controlling interactions of these cationic gemini's with counterions. Although effects of salt on single tail surfactants such as alkyltrimethylammonium and alkylpyridinium are well documented [25-27], ion specificity of the corresponding gemini surfactants have not been explored in detail, though these interactions are likely to be important for their self-assembly and phase behaviour. Our results showed that length of spacer determines size specific interaction of cationic gemini with different counterions and fixed distance between dicationic head group of G2, G4, and G6 acts as a surface template for counterions to organize in a controlled fashion leading to formation of aggregates of different morphologies. A key consequence is that the counterion effects are specific beyond Hofmeister series and that also the co-ions induces co-ion specific changes in surfactant behavior. Further, our studies show that adjusting headgroup structure it is possible to generate amphiphiles which can be used to bind specific metal ions in solution, for purposes such as water purification and mineral enrichment.

\section{ACKNOWLEDGEMENTS}

HBBG is supported by Finnish Academy and Sigrid Juselius Foundation. RS was additionally supported by Paulo foundation.

\section{SUPPORTING MATERIAL}

The supporting material can be downloaded from the journal website along with the article.

\section{REFERENCES}

[1] Zana R. Dimeric (gemini) surfactants: effect of the spacer group on the association behavior in aqueous solution. $J$ Colloid Interface Sci 2002; 248: 203-20. http://dx.doi.org/10.1006/jcis.2001.8104

[2] Menger F, Mbadugha BN. Gemini surfactants with a disaccharide spacer. J Am Chem Soc 2001; 123: 875-85. http://dx.doi.org/10.1021/ja0033178

[3] Grosmaire L, Chorro M, Chorro C, Partyka S, Zana R. Alkanediyl-alpha, omega-bis(dimethylalkylammonium bromide) surfactants 9 . Effect of the spacer carbon number and temperature on the enthalpy of micellization. J. Colloid Interface Sci 2002; 246: 175-81.

http://dx.doi.org/10.1006/jcis.2001.8001

[4] Menger FM, Keiper JS. Gemini surfactants. Angew Chem Int Ed 2000; 39: 1906-20.

http://dx.doi.org/10.1002/1521-

3773(20000602)39:11<1906::AID-ANIE1906>3.0.CO;2-Q

[5] Menger FM, Littau CA. Gemini surfactants: a new class of self-assembling molecules. J Am Chem Soc 1993; 115: 10083-90.

http://dx.doi.org/10.1021/ja00075a025

[6] Menger FM, Littau CA. Gemini-surfactants: synthesis and properties. J Am Chem Soc 1991; 113: 1451-2. http://dx.doi.org/10.1021/ja00004a077

[7] Ryhänen SJ, Säily VM, Parry MJ, et al. Counterion-controlled transition of a cationic gemini from submicroscopic to giant vesicles. J Am Chem Soc 2006; 128: 8659-63.

http://dx.doi.org/10.1021/ja060382u

[8] Kirby AJ, Camilleri P, Engberts JBFN, et al. Gemini surfactants: new synthetic vectors for gene transfection. Angew Chem Int Ed 2003; 42: 1448-57. http://dx.doi.org/10.1002/anie.200201597

[9] Badea I, Verrall R, Estrada $\mathrm{MB}$, et al. In vivo cutaneous interferon-gamma gene delivery using novel dicationic (gemini) surfactant-plasmid complexes. J Gene Med 2005; 7: 1200-14.

http://dx.doi.org/10.1002/jgm.763

[10] Badea I, Wettig S, Verrall R, Foldvari M. Topical non-invasive gene delivery using gemini nanoparticles in interferongamma-deficient mice. Eur J Pharm Biopharm 2007; 65: 414-22.

http://dx.doi.org/10.1016/j.ejpb.2007.01.002

[11] Ryhänen SJ, Säily MJ, Paukku T, et al. Surface charge density determines the efficiency of cationic gemini surfactant based lipofection. Biophys J 2003; 84: 578-87. http://dx.doi.org/10.1016/S0006-3495(03)74878-4

[12] Zana R. Dimeric and oligomeric surfactants. Behavior at interfaces and in aqueous solution: a review. Adv Colloid Inter Sci 2003; 97: 205-53.

http://dx.doi.org/10.1016/S0001-8686(01)00069-0

[13] Kabir-ud-Din FW, Khan ZA, Dar AA. 'H NMR and viscometric studies on cationic gemini surfactants in presence of aromatic acids and salts. J Phys Chem B 2007; 111: 8860-7. http://dx.doi.org/10.1021/jp070782j

[14] McLoughlin D, Delsanti M, Albouy MPA, Langevin D. Aggregates formation between short DNA fragments and cationic surfactants. Mol Phys 2005; 103: 3125-39. http://dx.doi.org/10.1080/00268970500250460

[15] Goddard ED. Polymer/Surfactant Interaction: Interfacia Aspects. J Colloid Inter Sci 2002; 256: 228-35. http://dx.doi.org/10.1006/jcis.2001.8066

[16] Jianga N, Lib P, Wanga Y. Aggregation behavior of hexadecyltrimethylammonium surfactants with various counterions in aqueous solution. J Colloid Inter Sci 2005 286: 755-60.

http://dx.doi.org/10.1016/j.jcis.2005.01.064

[17] Zana R, Benrraou M, Rueff R. Alkanediyl-.alpha.,.omega.bis(dimethylalkylammonium bromide) surfactants. 1. Effect of the spacer chain length on the critical micelle concentration and micelle ionization degree. Langmuir 1991; 7: 1072-75. http://dx.doi.org/10.1021/la00054a008

[18] Tejera-Garcia R, Connell L, Shaw WA, Kinnunen PKJ. Gravimetric determination of phospholipid concentration. Chem Phys Lipids 2012; 6: 689-95. http://dx.doi.org/10.1016/j.chemphyslip.2012.06.005

[19] Vitovic P, Alakoskela JM, Kinnunen PKJ. Assessment of drug-lipid complex formation by a high-throughput Langmuir- 
balance and correlation to phospholipidosis. J Med Chem 2008; 51: 1842-48.

http://dx.doi.org/10.1021/jm7013953

[20] Suomalainen $P$, Johans C, Soderlund T, Kinnunen PKJ. Surface activity profiling of drugs applied to the prediction of blood-brain barrier permeability. J Med Chem 2004; 47: 1783-88.

http://dx.doi.org/10.1021/jm0309001

[21] Padday JF, Pitt AR, Pashley RM. Menisci at a free liquid surface: Surface tension from the maximum pull on a rod. $\mathrm{J}$ Chem Soc Fr 1 1974; 71: 1919-31.

[22] Ryhänen SJ, Alakoskela JM, Kinnunen PKJ. Increasing surface charge density induces interdigitation in vesicles of cationic amphiphile and phosphatidylcholine. Langmuir 2005; 21: $5707-15$. http://dx.doi.org/10.1021/la0503303

[23] Ryhänen SJ, Säily VMJ, Kinnunen PKJ. Cationic lipid membranes-specific interactions with counter-ions. J Phys Condens Matter 2006; 18(28): S1139-50.

http://dx.doi.org/10.1088/0953-8984/18/28/S03
[24] Geng Y, Romstead SL, Menger F. Specific ion pairing and interfacial hydration as controlling factors in gemini micelle morphology. Chemical trapping studies. J Am Chem Soc 2006; 128: 492-501.

http://dx.doi.org/10.1021/ja056807e

[25] Knock MM, Main CD. Effect of counterion on monolayers of hexadecyltrimethylammonium halides at the air-water interface. Langmuir 2000; 16: 2857-65. http://dx.doi.org/10.1021/la991031e

[26] Subramanian V, Ducker WA. Counterion effects on adsorbed micellar shape: experimental study of the role of polarizability and charge. Langmuir 2000; 16: 4447-54. http://dx.doi.org/10.1021/la991245w

[27] Bijma K, Engberts JBFN. Effect of counterions on properties of micelles formed by alkylpyridinium surfactants. 1 . conductometry and ${ }^{1} \mathrm{H}-\mathrm{NMR}$ chemical shifts. Langmuir 1997; 13: 4843-49.

http://dx.doi.org/10.1021/la970171q 